\title{
EXCITING DEVELOPMENTS IN THE CHEMISTRY OF GOLD
}

\author{
William S. Rapson
}

Hydrogen bonding is a type of bonding which is very familiar to chemists, especially as manifested in compounds containing hydroxyl groups. It is a weak bond, but the energy of the reaction

$$
\begin{array}{ccc}
\mathrm{H} & \mathrm{H} \\
\mathrm{I} & \mathrm{O}-\mathrm{H} \cdots \mathrm{O}-\mathrm{R} \leftrightarrow \mathrm{R}-\mathrm{O} \cdots \mathrm{H} \cdots \mathrm{O}-\mathrm{R}
\end{array}
$$

for example, is sufficient to dictate the properties and structures of many R-OH compounds significantly. Thus in the liquid state or in solution, it may give rise to intermolecular interactions with the formation, especially in the case of compounds containing more than one hydroxyl group, of effectively polymeric structures. In the solid state, similar intermolecular interactions have been found to dictate the crystal structures of many hydroxyl compounds. Perhaps the simplest and best known examples of this are the crystal structures of the straight chain primary fatty alcohols and fatty acids. Intramolecular hydrogen bonding is also well known.

From the Inorganic Chemistry Institute of the Technical University of Munich there has now appeared a publication (H. SCHMIDBAUR, W. GRAF and G. MÜLLER, Angew. Chem., Int. Ed. Engl., 1988, 27(3), 417-419) which establishes an analogy between the role played by hydrogen bonding in determining the properties and structures of hydroxyl compounds, and that played by weak $\mathrm{Au} \cdots \mathrm{Au}$ bonding in determining the properties and structures of gold(I) compounds.

The paper begins by drawing attention to the wealth of indirect evidence which has emerged from structural and spectroscopic studies for the existence of an attractive interaction between gold(l) atoms of $\mathrm{d}^{10}$ configuration in both mono- and poly-nuclear gold(I) compounds. This interaction is seen as stemming from a mixing of the $6 s^{2}$ states, whose energy gap is reduced by relativistic effects. The phenomenon is a rare one, possibly exhibited most strongly by gold. In the case of the neighbouring element mercury such effects are already much less pronounced. The interaction

$$
\begin{array}{ccc}
\mathrm{L}-\mathrm{Au}-\mathrm{L} & \mathrm{L}-\mathrm{Au}-\mathrm{L} \\
+ & \leftrightarrow & : \\
\mathrm{L}-\mathrm{Au}-\mathrm{L} & & \mathrm{L}-\mathrm{A} u-\mathrm{L}
\end{array}
$$

occurs perpendicular to the principal axis of the linearly two-coordinated gold(I) atoms. It can give rise either to weak intermolecular bonding between $\mathrm{Au}$ atoms in gold(I) compounds, with the formation of catenated or layered aggregations (effectively polymers) of molecules linked via $\mathrm{Au} \cdots \mathrm{Au}$ bonds, or to weak in- tramolecular bonding between $\mathrm{Au}(\mathrm{I})$ atoms in cases where close approach between such atoms within one and the same molecule is feasible.

Structurally, such bonding manifests itself in the solid state in $\mathrm{Au} \cdots \mathrm{Au}$ interatomic distances which are sometimes significantly less than $3.0 \AA$. A part from numerous such manifestations, however, the authors point out that they have found no recorded proof of the existence of such interactions between gold(I) atoms, and no successful attempts to measure their strengths. They then describe studies which provide such proof, and demonstrate that the energy of the $\mathrm{Au} \cdots \mathrm{Au}$ interaction lies in the order of 7-8 $\mathrm{kcal} \mathrm{mol}^{-1}$, which is comparable with that involved in hydrogen bonding. They also show that the energy involved in such bonding is sufficient, as it is in the case of hydrogen bonding, to determine the conformation of some structures within which it occurs.

This established analogy between the effects of hydrogen bonds in hydroxylic compounds and $\mathrm{Au} \cdots \mathrm{Au}$ bonds in $\mathrm{Au}(\mathrm{I})$ compounds should do much to facilitate an understanding of the properties and behaviour of the latter. More importantly, however, greater appreciation of the implications of $\mathrm{Au} \cdots \mathrm{Au}$ bonding has already provided a basis for further significant developments by Prof. Schmidbaur's research school on gold, where there is an active interest in the thermal, chemical and photochemical deposition of gold, for application in electronics and electron microscopy. From this point of view, not only gold clusters, in which gold atoms are directly bonded to one another, but also organogold compounds in which several gold atoms are bonded via a common carbon atom are of special importance. The close proximity of the gold atoms in such compounds should not only lead to clearly recognizable Au $\cdots \mathrm{Au}$ bonding relationships but should also facilitate metal nucleation which is important for the controlled deposition of gold. Three further papers have been published in this connection, and a fourth is in press.

The first of these (H. SCHMIDBAUR, F. SCHERBAUM, B. HUBER and G. MÜLLER, Angew. Chem., Int. Ed. Engl., $1988,27(3), 419-421$ ) describes the synthesis of the first triauriomethane compound. In this the three gold atoms were found to be about equidistant from the carbon atom. Pairwise, however, they form angles with the carbon atom which are significantly less than the tetrahedral angle of $109^{\circ}$ and the $\mathrm{Au}-\mathrm{Au}$ interatomic distances average $3.18 \AA$, despite the repulsion to be expected from the large $\mathrm{PPh}_{3}$ ligands to which they are 
also bonded. Clearly the $\mathrm{Au} \cdots \mathrm{Au}$ interactions have a significant effect in determining the structure and conformation of the compound.

The second paper (F. SCHERBAUM, B, HUBER, G. MÜLLER and H. SCHMIDBAUR, ibid., 1988, 27(11), 1542-1544) describes an alternative route to triauriomethanes which exploits the $\mathrm{CH}$ acidity of 2,4,4trimethyl-4,5-dihydrooxazole. The new product, generated in an unusual way, exhibited a surprisingly high acceptor strength for further $\mathrm{Au}(\mathrm{I})$ ions, which led to the formation of a novel cluster containing four gold atoms all in the oxidation state $+\mathrm{I}$.

In the third paper (F. SCHERBAUM, A. GROHMANN, B, HUBER, C. KRÜGER and H. SCHMIDBAUR, ibid., 1988, $27(11), 1544-1546)$ this discovery that highly aurated compounds containing two or more gold atoms on one and the same carbon atom readily bond further gold(I) units $\mathrm{LAu}^{\oplus}\left(\mathrm{L}=\mathrm{R}_{3} \mathrm{P}\right)$ is developed further and the term 'aurophilicity' is introduced to describe this property, which is seen as a consequence of relativistic effects. In the reaction, the coordination number of the polyaurated $\mathrm{C}$ atoms is increased beyond 4 , so that, for example, tetragonal-pyramidal structures with close $\mathrm{Au} \cdots \mathrm{Au}$ contacts are formed. It is indicated that a simple molecular orbital scheme for the cations $\left[\mathrm{RC}(\mathrm{AuL})_{4}\right]^{+}$shows full occupation of the bonding orbitals, which is taken to explain, at least qualitatively, the unexpected ease of formation of such systems. The resulting bonds, directed toward the $\mathrm{C}$ atom, are complemented by contributions from $\mathrm{Au} \cdots \mathrm{Au}$ interactions originating in relativistic effects as discussed above.

Such considerations led the authors to seek synthetic routes to tetraauriomethanes, which because of their presumably still greater aurophilicity, would make it possible to prepare even more highly coordinated auriomethanes. In this they were successful and they describe the preparation and characterization of the compound

$$
\left[\left(\mathrm{Ph}_{3} \mathrm{PAu}\right)_{6} \mathrm{C}\right]^{2 \oplus}\left[\mathrm{CH}_{3} \mathrm{OBF}_{3}\right]_{2}^{-} \text {. }
$$

Although the central carbon atom in this compound could not be detected by NMR spectroscopy, X-ray structure analysis revealed the presence of an only slightly distorted octahedron of gold atoms, the crystallographic inversion centre of which is occupied by a carbon atom. (Further evidence for the interstitial carbon was obtained by mass spectrometry.) Since a $\mathrm{Ph}_{3} \mathrm{P}$ ligand is attached to each of the gold atoms, the $\mathrm{Au}(\mathrm{I})$ centres are each bonded classically by sp hybrid bonds in a linear fashion to one $P$ atom and to the central carbon atom. A molecular orbital diagram is presented which describes the bonding between the central carbon atom and the six gold atoms. A reduction in energy due to overlap of the $\mathrm{C}$ and $\mathrm{Au}$ orbitals is improved considerably by the lowering of the energy levels of these orbitals by relativistic contraction.
The average value $(3.003 \AA$ ) of the $\mathrm{Au} \cdots A \mathrm{Au}$ contacts along the edges of the octahedron indicates the existence of weak $\mathrm{Au} \cdots \mathrm{Au}$ bonding, which, as indicated above, involves a lowering of energy of 6-8 $\mathrm{Kcal} \mathrm{mol}^{-1}$. Even if this amount must be reduced in the cluster owing to the polycoordination of each metal atom, the twelve edges of the cluster give rise in total to a considerable lowering of energy upon aggregation. This effect is seen as providing an explanation for aurophilicity of the tetrauriomethanes $\mathrm{C}(\mathrm{AuL})_{4}$ toward $\mathrm{LAu}^{\oplus}$.

Finally, in a most recent paper, the isolation and structural characterization of the intermediate monocation $\left[\left(\mathrm{Ph}_{3} \mathrm{PAu}\right)_{5} \mathrm{C}\right]^{\oplus}$ in the form of its complex with the $\mathrm{BF}_{4}$ anion has been reported. (F. SCHERBAUM, A. GROHMANN, G. MÜLLER and H. SCHMIDBAUR, ibid, 1989, $28(4)$, in press). This cation has a trigonal-bipyramidal structure (see figure below) in excellent agreement with molecular orbital diagrams.

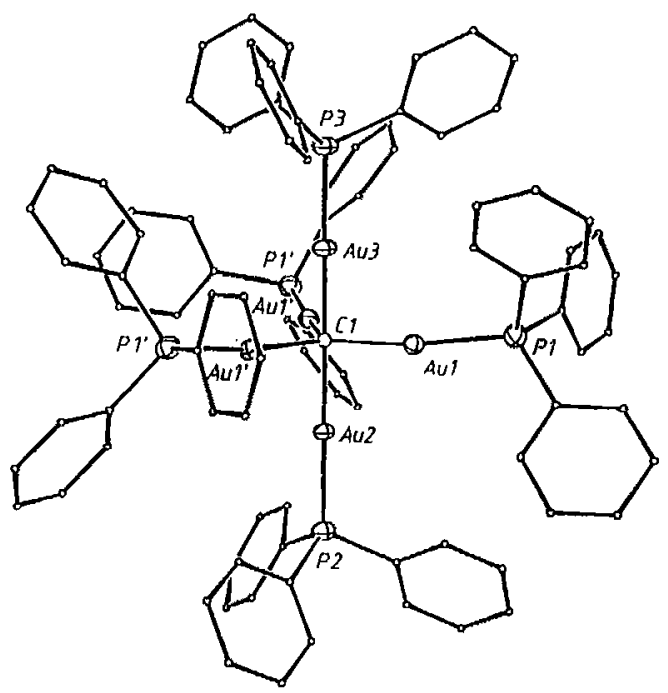

Molecular structure of the cation $\left[\left(\mathrm{Ph}_{3} \mathrm{PAu}\right)_{5} \mathrm{C}\right]^{\oplus}$. (Diagram courtesy Prof. Dr. H. Schmidbaur and Angewandte Chemie)

In the light of these findings certain earlier observations are discussed. What is significant, however, is that as a result of this work at the Technical University of Munich, a new class of carbido gold clusters is emerging. These can, as a result of the aurophilicity of polyauriomethanes, be prepared directly and in high yield. This contrasts with the position in regard to homoatomic gold clusters, which are still accessible only by somewhat alchemistic methods. Carbon-centred metal clusters of other types have been studied (e.g. $\left(\mathrm{CLi}_{6}\right)^{2 \oplus)}$ and compounds of this type have been named 'porcupine' compounds.

These are all exciting developments in the chemistry of gold and we look forward to further publications in this area from the group led by Prof. Dr. H. Schmidbaur in Munich. 